\title{
Defogging Strategy for Protective Eye Goggles to Prevent Microorganism Transmission While Performing Neurosurgical Procedures
}

\author{
Adesh Shrivastava ${ }^{1}$ Sumit Raj ${ }^{1}$ Pradeep Chouksey \\ ${ }^{1}$ Department of Neurosurgery, All India Institute of Medical \\ Sciences, Saket Nagar, Bhopal, Madhya Pradesh, India
}

J Neurosci Rural Pract 2021;12:447-449.

Leonardo Da Vinci said, "simplicity is the ultimate sophistication." ${ }^{1}$ This applies to solutions for any problem, including those of the medical profession. Unlike medical specialties, surgeons are confronted with the additional danger of theCOVID-19 viral transmission intraoperatively. Reports suggest conjunctiva as one of the portals for entry of SARS$\mathrm{CoV}-2$, for which use of protective eye goggles is warranted..$^{2-4}$ However, with the use of commonly available protection goggles, fogging while operating makes their use cumbersome (- Fig. 1)..$^{5}$ Even with the best available antifogging coated goggles, a thin layer of fluid forms on the inside, which deteriorate the vision, thereby putting the patient at risk (-Fig. 2). Surgeons and surgical staff around the world face this issue and often need to take off the goggles for cleaning during the procedure. This puts the surgeon at risk due to breach in protection. The commercially available solution to this is the powered air circulating headgear. But in addition to deteriorating the verbal communication between the operating team members, they are highly cost-restrictive, especially for the resource-constrained settings. The reason behind the formation of fog on the inside of the protective goggles is the accumulation of sweat vapors which condense on the cold glass. This happens due to the absence of ventilation inside. One understands that if sweat vapors can escape out from the inside of the goggles, it would prevent fog formation. This can be achieved by attaching a circuit for clean air/gas inflow/outflow in the existing protective goggles. We suggest the use of a nasal prong cannula, which is a readily available disposable in any operation theater (OT). After the surgeon is donned with the personal protective equipment (PPE) and scrubbed, an assistant places a nasal prong cannula above the glabela on the forehead pointing downward and secures it behind the head followed by placement of the

\author{
Rakesh Mishra ${ }^{1}$ Surya Prakash¹ Amit Agrawal ${ }^{1}$
}

Address for correspondence Adesh Shrivastava, MCh, Department of Neurosurgery, All India Institute of Medical Sciences, Saket Nagar, Bhopal 462016, Madhya Pradesh, India

(e-mail: dr.adesh.shrivastava@gmail.com).

eye protection goggles over it ( $\boldsymbol{- \text { Fig. }} \mathbf{3}$ ). The next step is to arrange for the source of clean air or an inert/nonirritant gas for this circuit. Other than a commercially available powered air purifying respirator (PAPR) pump, there are other sources of clean airflow easily available in any OT. These include the compressed air points (medical or surgical) in OT pendants, central oxygen points, and even oxygen cylinders. Using a flowmeter, the flow of air/gas from any of these sources can be titrated and channeled to the inside of the goggle by attaching it to the nasal prong cannula worn by the surgeon. For the compressed air points, the routinely available oxygen flow meter will require modification of the connector accordingly. As the final step, regulated flow of air/oxygen is initiated and titrated at an effective and comfortable level. The small gaps created by the cannula tubing while entering on the inner side of the googles shall allow air/gas to escape along with the sweat vapors. This will thereby limit fog formation ( - Fig. 4). At the end of the procedure, the nasal prong tubing is discarded similar to the other disposable PPE items.

With the emergence of COVID-19 pandemic, health care specialties have witnessed significant changes in the practice patterns. As more knowledge is gained about the virology and pathobiology of SARS-CoV-2, guidelines emerged to curtail the transmission. Although the primary route of entry of SARS-CoV-2 is respiratory, further research has suggested other portals in the human body for entry of this virus. It was found that SARS-CoV-2 can be transmitted by ocular route via blood-mixed aerosols and particulate matter.-4,6 Hence, eye goggles and safety face shields are mandatorily employed to protect eyes and curtail ocular transmission of SARS-CoV-2. ${ }^{4}$ SARS-CoV-2 induces inflammation and increases expression of angiotensin-converting enzyme 2 (ACE2) receptor and entry protease TMPRSS2 on the published online

February 9, 2021
DOI https://doi.org/

10.1055/s-0041-1723062

ISSN 0976-3147.
(C2021. Association for Helping Neurosurgical Sick People.

This is an open access article published by Thieme under the terms of the Creative Commons Attribution-NonDerivative-NonCommercial-License, permitting copying and reproduction so long as the original work is given appropriate credit. Contents may not be used for commercial purposes, or adapted, remixed, transformed or built upon. (https://creativecommons.org/licenses/by-nc-nd/4.0/).

Thieme Medical and Scientific Publishers Pvt. Ltd. A-12, 2nd Floor, Sector 2, Noida-201301 UP, India 


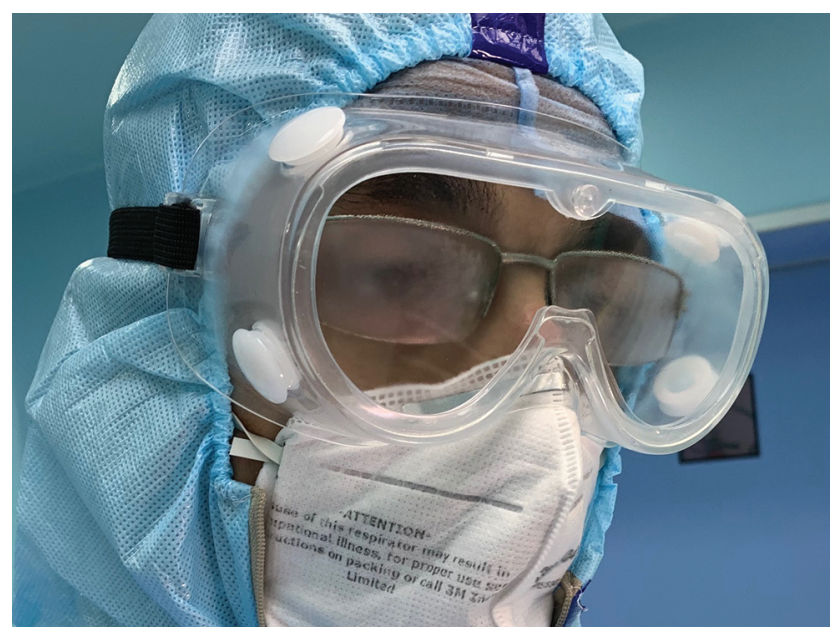

Fig. 1 Fog formation on the inside of the protective eye goggles, which leads to poor vision.

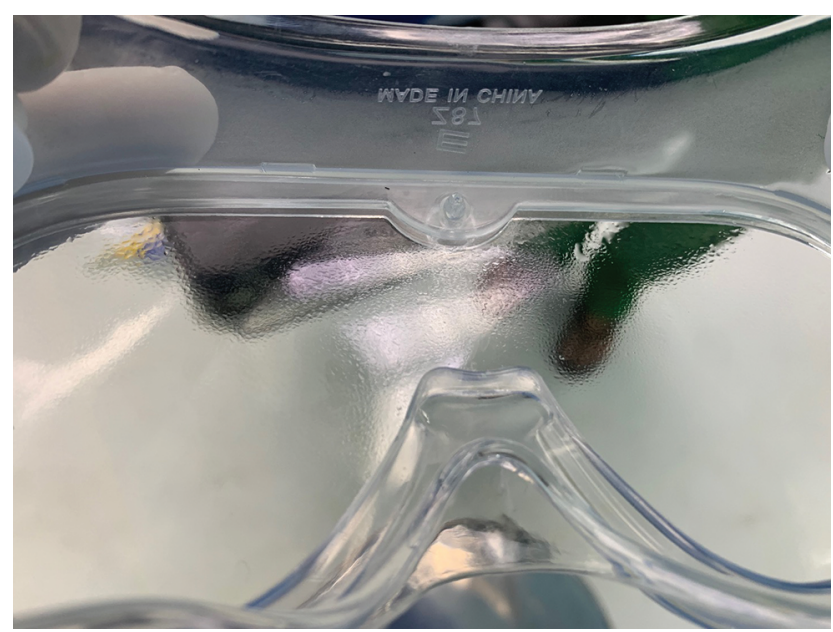

Fig. 2 Goggles with antifogging coating have the phenomenon of forming a fluid layer, which deteriorated vision by chromatic aberration.

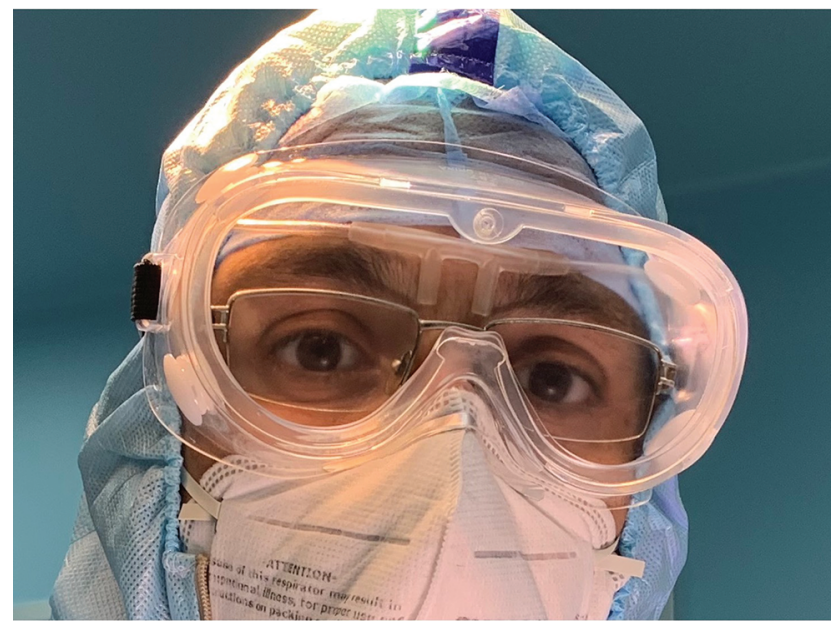

Fig. 3 Nasal prong cannula placed at the level of glabela and pointing downward. The protective eye goggles are then worn over it.

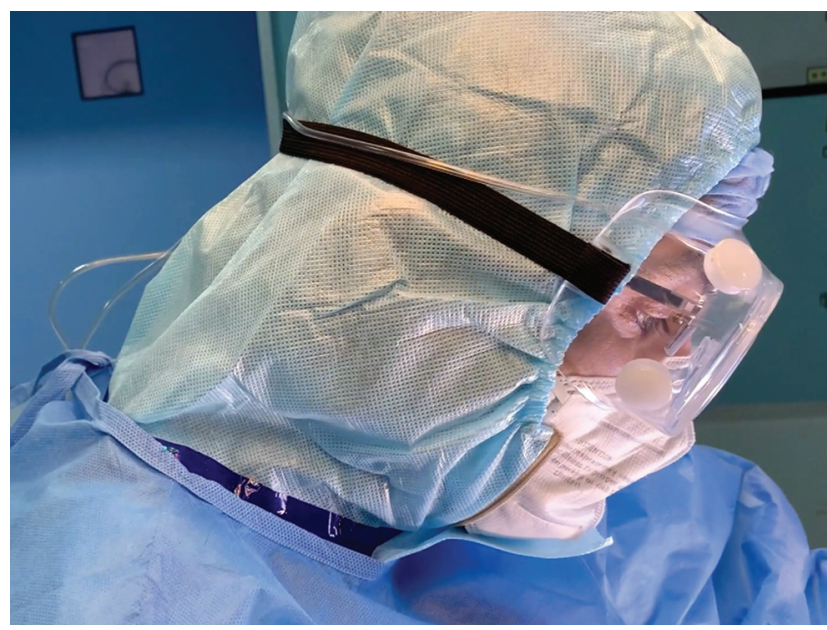

Fig. 4 The airflow using the cannula is titrated to a comfortable level to limit fog formation while the surgeon is operating.

conjunctival, limbal, and corneal epithelium. ${ }^{2}$ Quantitatively, these receptor proteins were found to be low in ocular surfaces, yet there are reports of detection of SARS-CoV-2 RNA particle in conjunctive and tear film. ${ }^{3,7}$ Many patients infected with SARS-CoV-2 have reported eye signs, especially follicular conjunctivitis as one of the presenting features. ${ }^{4} \mathrm{As}$ the knowledge about SARS-CoV-2 pandemic is increasing, we will eventually know the precise transmission potential of this virus through ocular surfaces. But at this stage, it is wise to take every necessary protection measure, in order to prevent the transmission. It is, therefore, recommended to use protective eye goggles and face shield/visors to protect eyes. ${ }^{4}$ Often due to fogging in the spectacles and inner surface of these goggles, vision gets obscured. ${ }^{8}$ As a result, these become uncomfortable to wear and cannot be used continuously for a longer duration of time. This is a well-known concern for all surgeons who have to wear these eye protection goggles while operating. Antifog sprays are used to reduce fogging by virtue of their surfactant effect. ${ }^{9}$ But even with the use of the best available antifogging sprays or coatings, as condensation happens, a thin layer of fluid forms on the inner surface, which ultimately deteriorates the vision by chromatic aberration. The commercially available solution to prevent fogging is the powered air purifying respirators (PAPRs) with a headgear. But apart from being highly cost-restrictive, they also lead to significant deterioration in verbal communication between the team members in such critical areas. ${ }^{10}$ Proposed technique can facilitate the use of routinely available eye protection goggles without impairing the visibility, due to fog or condensation film, and reduce the frequent handling of eye goggles by keeping the surgeon comfortable for long hours without added cost. Using nasal prong cannula may meet opposition, because it is not a standalone eye-protective device, but an add-on to the protective eye goggles. Individuals may oppose using another device on top of unwieldy personal protective gear to prevent fogging. 


\section{Conflict of Interest}

A.S. reports pending patent application at IPO. The remaining authors do not report any conflict of interest.

\section{References}

1 Glasgow P. Simplicity: the ultimate sophistication. Br J Sports Med 2014;48(5):345-345

2 Collin J, Queen R, Zerti D, et al. Co-expression of SARS$\mathrm{CoV}-2$ entry genes in the superficial adult human conjunctival, limbal and corneal epithelium suggests an additional route of entry via the ocular surface. Ocul Surf 2020 (e-pub ahead of print). DOI: 10.1016/j.jtos.2020.05.013

3 Zhou L, Xu Z, Castiglione GM, Soiberman US, Eberhart CG, Duh EJ. ACE2 and TMPRSS2 are expressed on the human ocular surface, suggesting susceptibility to SARS-CoV-2 infection. Ocul Surf 2020;18(4):537-544

4 Dockery DM, Rowe SG, Murphy MA, Krzystolik MG. The ocular manifestations and transmission of COVID-19: recommendations for prevention. J Emerg Med 2020;59(1):137-140
5 Lombardi DA, Verma SK, Brennan MJ, Perry MJ. Factors influencing worker use of personal protective eyewear. Accid Anal Prev 2009;41(4):755-762

6 Wang W, Xu Y, Gao R, et al. Detection of SARS-CoV-2 in different types of clinical specimens. JAMA 2020;323(18):1843-1844

7 Lange C, Wolf J, Auw-Haedrich C, et al. [What is the importance of the conjunctiva as a potential transmission pathway for SARSCoV-2 infections?] Ophthalmologe 2020;117(7):626-630

8 Crebolder JM, Sloan RB. Determining the effects of eyewear fogging on visual task performance. Appl Ergon 2004;35(4): 371-381

9 Gurnani B, Kaur K, Mishra K, Venkatesh R. A simple solution to prevent microscope eyepiece fogging and spectacle fogging in COVID-19 era. Indian J Ophthalmol 2020;68(8):1712-1713

10 Round M, Isherwood P. Speech intelligibility in respiratory protective equipment - Implications for verbal communication in critical care. Trends in Anaesthesia and Critical Care 2020 (e-pub ahead of print). DOI: 10.1016/j.tacc.2020.08.006 